\title{
What does 'beyond compliance' look like for the Scottish salmon aquaculture industry?
}

\author{
Clara McGhee ${ }^{1 *}$, Lynne Falconer ${ }^{1}$, Trevor Telfer ${ }^{1}$ \\ ${ }^{1}$ Institute of Aquaculture, University of Stirling, Stirling, Scotland, FK9 4LA \\ *Corresponding author: \\ Email: claramcghee@hotmail.co.uk
}

Other author contact details:

Lynne Falconer

Email: lynne.falconer1@stir.ac.uk

Trevor Telfer

Email: t.c.telfer@stir.ac.uk

Declarations of interest: none.

Accepted refereed manuscript of: McGhee C, Falconer L \& Telfer T (2019) What does 'beyond compliance' look like for the Scottish salmon aquaculture industry?. Marine Policy, 109, Art. No.: 103668. DOF: https://doi.org/10.1016/j.marpol.2019.103668

(C) 2019, Elsevier. Licensed under the Creative Commons Attribution-NonCommercialNoDerivatives 4.0 Internationa http://creativecommons.org/licenses/by-nc-nd/4.0/ 


\title{
What does 'beyond compliance' look like for the Scottish salmon aquaculture industry?
}

\begin{abstract}
Salmon farming has developed significantly since its inception in Scotland. It is now an established part of the rural communities in which it operates, is a key contributor to the Scottish and UK economies and has an important role in meeting the growing global demand for food. However, the Scottish salmon industry is subject to a number of regulatory, environmental and social licence challenges, amongst others, that must be overcome if it is to continue to develop and expand to meet ambitious targets for increasing production. Beyond compliance is one way in which the industry can seek to overcome such challenges. Based on qualitative data gathered from analysis of industry reports, stakeholder interviews and questionnaires, this paper i) provides an overview of challenges currently facing Scottish salmon farming, ii) presents beyond compliance measures already taking place, iii) discusses industry opportunities and challenges in terms of beyond compliance, and iv) offers suggestions for the future of beyond compliance, including incentives and ways in which it could be effectively measured.
\end{abstract}

\section{Key words:}

Aquaculture, beyond compliance, environmental regulation, salmon farming, social licence, sustainability.

\section{Introduction}

The growth of Atlantic salmon farming in recent years, and continued projected growth in many countries, has raised concerns amongst stakeholders about the sustainability of the industry and its practices, from regulators to lobbyists, governments and consumers alike (Amberg and Hall, 2008; Whitmarsh and Palmeiri, 2011; Shepherd and Little, 2014; Salgado et al., 2015). Issues include escape events, feed sustainability, medication use and impacts to the wider environment and biodiversity (Olsen and Osmundsen, 2017). 
As part of their licence to operate, salmon producers must adhere to statutory requirements that are determined by the relevant regulatory authorities. Both producers and regulators have a role in ensuring industry compliance with the environmental limits set by regulation. Such limits are usually defined based on scientific evidence or environmental modelling (FAO, 2009) and aim to minimise impacts on water quality, the seabed and the ecological status of the marine environment immediately surrounding salmon cages. Porter (1991) argued that strict environmental regulation can be beneficial by enhancing competitiveness and encouraging innovation to reduce impact and increase efficiency. However, regulations and policy can also constrain development (Knapp and Rubino, 2016), therefore there is a need to strike a balance and have a regulatory regime that is fitfor-purpose. This is particularly important for salmon farming, because even if statutory requirements are met, apparent environmental impacts and, in some instances, a lack of trust in regulatory regimes has contributed to a negative public image in many producer (and consumer) countries (Olsen and Osmundsen, 2017; Hynes et al., 2018).

The Scottish salmon aquaculture industry is in a period of transition and growth, with ambitious targets to double production by 2030 (Scotland Food and Drink, 2016). The projected growth of Scottish salmon farming presents a major opportunity for the industry, the rural communities in which companies operate and the Scottish and UK economies as a whole. However, this growth also comes with the risk of increased environmental impact and biological challenges, with consequences for company reputation, social licence to operate, profit, liability and damage to the brand and value of premium Scottish salmon. These risks led to a Scottish Parliament commissioned report on the environmental impact of Scottish salmon farming (Tett et al., 2018), as well as two separate Scottish Government inquiries into the environmental and economic impacts of the industry and its growth in Scotland, held between January and May 2018 by the Rural Economy and Connectivity (REC) and Environment, Climate Change and Land Reform (ECCLR) committees.

One way in which salmon producers can contribute to overcoming environmental, regulatory and public perception challenges is by going 'beyond compliance'. The concept of beyond compliance has been embraced by the Scottish Environment Protection Agency (SEPA), which adopted a new strategy for environmental regulation in response to growing concerns over Scotland's use of global resources (SEPA, 2016). One of the key 
drivers behind this new approach is the need for a more sustainable society as it is estimated that Scotland uses three planets worth of resources (SEPA, 2016; Global Footprint Network, 2018). SEPA now consider their role to be two-fold; first, to ensure regulated activities fulfil statutory requirements and reach compliance, and second, to assist regulated entities to go 'beyond compliance' (SEPA, 2016).

Beyond compliance is a practice seen across many industries and businesses globally and can be considered, in simple terms, as anything a company does additional to their legal operational requirements. In the past, most companies regarded legal compliance as fulfilling their social obligations. Few companies would implement beyond compliance measures, unless resulting in increased profit (Gunningham et al., 2006). However, this is changing, particularly in advanced economies, where many companies now see their social and environmental responsibilities as separate, and in addition to, their legal ones. Furthermore, going beyond statutory requirements can also increase public support (Lee et al., 2019). Consequently, as noted by Borck and Coglianese (2011), beyond compliance is usually born out of economic, managerial or moral motivation.

Across all sectors, there are questions regarding the concept of beyond compliance, potential incentives and how this differs from regulatory requirements and a company's social and environmental responsibilities. Environmental regulation usually requires resource users to follow a series of rules and meet certain standards. Standards provide uniformity and discipline (Busch, 2000), allowing actions to be judged by the same criteria. They can also reduce uncertainty (Flynn and Hacking, 2019), as a decision-maker can assess if an action is compliant with the numerical value(s) assigned to the standard or qualitative indicator. However, standards can change behaviour, as activities work on achieving the set criteria, which may be counter to another aspect of the business (Busch and Bowker., 2011). In contrast, beyond compliance is voluntary, and there are different ways that a company can go beyond compliance (Borck and Coglianese, 2011). Companies can evaluate the trade-offs and cost-benefits of going beyond compliance and then decide on the most appropriate course of action for them.

Globally, there already appears to be a move towards activities which are additional to regulatory compliance in the salmon farming industry, with more companies introducing 
voluntary self-regulation, corporate social responsibility (CSR) measures and increasing the importance of third parties and certification schemes such as the Aquaculture Stewardship Council (ASC) and Global Salmon Initiative (GSI). CSR practices include providing benefits to local communities and charitable donations and can be linked to the social licence to operate (Huemer et al., 2010; Vince and Haward, 2017), whereas certification schemes are arguably driven by consumer and retailer demand (Bush, 2018).

National bodies or producer organisations such as the Scottish Salmon Producers Organisation (SSPO) can also play an important role in encouraging companies to go beyond compliance. An example is the SSPO Code of Good Practice (SSPO, 2015) which builds on the Scottish regulatory framework and specifies additional production standards their members must meet. Significant investment by individual companies also drives innovation in technology, infrastructure and feed used by the industry, with the objective of reducing environmental impact whilst increasing yield and ultimately, profit. If beyond compliance is to be recognised and rewarded, there is a need to evaluate the understanding of different stakeholders and, in the case of producers, identify potential constraints that might prevent them going beyond compliance. While there are obvious benefits for companies to go beyond compliance, such a move could require resources that not all companies have, so there is a risk this could lead to a tiered system and an uneven playing field amongst companies.

The aim of this study is to explore beyond compliance in the context of Atlantic salmon farming in Scotland through reference to reports and other literature, qualitative data analysis and consultation with industry stakeholders. First, challenges for industry growth and issues related to the existing regulatory framework are identified. Then the concept of 'beyond compliance' is evaluated in more detail. Finally, recommendations are made which could support the industry to implement approaches which would be considered as going beyond compliance. Whilst the examples presented are Scotland based, the findings have relevance and implications for all salmon producing countries and other aquaculture sectors who face similar environmental, development and public perception challenges or who are also governed by complex and proscriptive regulatory frameworks. 


\section{Methods}

A multi-strategy design (Robson and McCartan, 2016) was used for this research, combining different approaches of qualitative data collection and analysis. The first step involved a search of relevant literature to inform the background and discussion and to develop questionnaires and interviews. This comprised published, grey literature but also included Scottish Government reports, evidence from the 2018 REC and ECCLR committee inquiries, industry reports and media publications. Following appraisal of this secondary data, semi-structured interviews were conducted with employees of salmon producers and industry bodies, either face-to-face or via telephone. Online questionnaires were used for supermarkets and regulators and licensors.

\subsection{Research participants}

The research participants fell into four distinct groups: employees of Scottish salmon producers with responsibilities for environmental compliance; government regulators and licensing bodies; fishery and seafood managers for leading UK supermarkets; and industry bodies (Table 1). Participants from these four groups were targeted for involvement as it was felt that they would have sufficient experience with this topic and the range of stakeholders would give a balanced view, drawing on different industry interests and opinions.

\section{*INSERT TABLE 1 HERE *}

The multi-strategy approach accommodated for the diversity in participant groups, and the different forms of information sought from each. Furthermore, it enabled a wider range of research questions to be addressed and allowed for differences in participants' involvement, experience and knowledge of the industry and research topic. Project constraints including geographical location of participants, cost and time were also considered when selecting the methods used. 
In the results section, respondents have been allocated numbered codes (see Table 1) where quotes are used. This makes it possible to determine whether the same respondent has been quoted several times, or if there are viewpoints from several respondents or different participant groups.

\subsection{Semi-structured interviews}

A set of core questions (Appendix A) were used to guide the interviews (Matthews and Ross, 2010), whilst allowing for flexibility in wording, running order and inclusion of unplanned questions based on the participants responses and flow of the interview (Robson and McCartan, 2016).

Semi-structured interviews were used for the producers and the industry body. These were considered key informants as they would be involved in designing or implementing any beyond compliance initiatives. The participants with responsibility for environmental compliance represented a number of Scottish salmon producers and thus a range in company size, financial value, access to technology and geographical locations of their farms. Semi-structured interviews were determined to be the most appropriate method for this participant group as it accommodated for a variety of opinions, experiences and responses to questions.

Twelve people from salmon and trout producers were contacted, resulting in six participants from five companies (four salmon producers and one trout producer) being interviewed. In 2017, only eight companies were authorised to produce and were actively producing Atlantic salmon in Scotland (Marine Scotland Science, 2018). Thus the research participants provided a good representation of the current Scottish industry. Of the six participants, one was a managing director of a company, one head of technical operations and the other four were responsible for environmental compliance, one of which was from a trout producer as trout farmed in sea cages are under the same legislation as salmon. One respondent from an industry representation body was also interviewed. 


\subsection{Online questionnaires}

Online questionnaires were used for the employees of UK supermarkets and industry regulators and licensors as it was felt their role in beyond compliance was more of guidance rather than actual implementation.

Bristol Online Surveys (Jisc, 2018) was used to design and carry out the questionnaires, which comprised of 19 questions for regulators (Appendix B) and 15 questions for supermarkets (Appendix C). Questionnaire responses were obtained from three supermarkets and four regulatory and licencing bodies.

\subsection{Nvivo data analysis}

All data was analysed using the software programme, Nvivo [QSR International Pty Ltd, Melbourne Australia], as it allowed for all data to be organised, categorised and analysed on one platform, including interview audio recordings, online questionnaire responses and secondary data sources. Analysing the data in this way enabled identification of reoccurring themes and the grouping of data within these themes. This organisation of data helped to inform the structure of the results and discussions sections of this paper. 


\section{Results}

\subsection{Challenges for industry growth}

Although all respondents were optimistic about the future growth of the industry, a number of challenges were identified that presented potential threats or barriers to expansion (Table 2). The most commonly identified challenge to growth was the difficulty of finding new sites that are appropriate for fish farm development. Without suitable sites, the industry cannot hope to achieve the 2030 targets, of which many respondents considered to be ambitious. The challenge of finding new sites appeared to be twofold: firstly, due to the current regulatory framework, specifically the "very stringent governance and planning processes", and secondly, due to local opposition. Overall, this challenge was seen to be greater for the smaller producers due to the costs, technology and resourcing implications that are less likely to constrain larger companies when exploring possible site locations.

\section{*INSERT TABLE 2 HERE*}

Biological constraints, relating specifically to sea lice and wider health issues, such as gill disease, were also seen as a challenge. Recent years have challenged the industry in terms of recorded lice numbers and disease outbreaks but there was a general consensus amongst producers that this was being brought under control due to proactive measures being taken by companies. Despite this, biological risks remain due to the dynamic and unpredictable nature of the marine environment.

Social licence was also identified by respondents as a potential barrier to growth. This was largely seen by the industry as an image issue, fuelled by vocal lobbyists and negative media coverage, contributing to poor public perception and opposition to industry expansion. Most producers found this frustrating as they considered the industry to be striving for continual improvement and thus felt that the public should trust that they are operating responsibly and are strictly regulated. Conversely, the regulators and licensors and supermarkets identified social licence as an issue of industry transparency and accountability to the public, and felt that more could be done to rectify the problem (and 
subsequently build the public trust that the producers' desire). However, all respondents universally agreed that the industry must have a social licence to expand and steps must be taken to achieve this.

Lastly, some regulator and supermarket respondents noted the overall sustainability of the industry as being a key challenge for growth, with some suggesting the industry was not operating in a sustainable fashion under the current regulatory regime. Whilst sustainability is a very broad topic that encompasses many challenges in its own right, issues relating to co-existence with wild fishery interests and other marine users, medication use and environmental footprints of sea cages were specifically identified. One regulator stated that a broader stewardship approach was required by producers to ensure overall industry sustainability.

\subsection{Issues associated with existing regulatory framework}

Whilst the majority of respondents believed the Scottish salmon industry to be strictly regulated and done so to a high standard, many issues and areas for improvement were identified across all respondent groups. There was a common opinion that the regulatory framework needs to be streamlined, simplified and modernised to effectively and specifically support the industry, both now and in the future, while maintaining environmental stewardship (Text Box 1).

"Therefore, we need to ensure there is an appropriate balance found between maintaining strong regulation in Scotland whilst not stifling industry investment and innovation in the salmon aquaculture sector, which might risk the industry falling behind its salmon competitors such as Norway and Chile."

(Rural Economy and Connectivity (REC) Committee Inquiry Evidence: Marks and Spencer, April 2018)

Text Box 1

Many respondents noted the duplication of information required during the consenting and licencing process, both for new sites or changes to existing ones. This can add additional costs and time to the already expensive and lengthy consenting process, potentially exacerbated by resourcing issues within regulatory bodies themselves. In addition, it was 
noted to be over-complicated and unclear as to which regulatory body took responsibility for what, often caused by an overlap of responsibilities between regulators.

Furthermore, a number of respondents described the regulatory framework as fragmented and unfit for purpose but there was a division in opinion when it came to the overall effectiveness of the current framework. This largely split respondent opinions into two groups: those who felt the regulatory framework was effectively serving the industry (Text Box 2), and those that did not (Text Box 3).

"I think it is effective and efficient in terms of assessing and granting the required regulatory consents and I think these consents are necessary and successful at protecting the environment. However, the whole system and the credibility of the industry are being undermined by a lack of post-consent monitoring and enforcement and a serious deficit in scientific data on which such monitoring can be based."

(Online questionnaire: Regulator / Licensing Body (REG 01), June 2018)

"I think it serves the industry effectively but it is fragmented and it doesn't join seamlessly, so there is a need for one of the regulators, I think, to take an overarching role on environmental performance." (Interview: Employee of salmon producer (PROD 01); June 2018)

Text Box 2

"Salmon farming is more an activity than development, notwithstanding the equipment required to do it, and the effective or otherwise management of that activity lies at the root of most issues currently facing the industry... A single upfront yes / no consenting in perpetuity for development of this type of industry in an unpredictable marine environment is clearly unfit for purpose."

(Online questionnaire: Regulator / Licensing Body (REG 02), June 2018)

"The way SEPA regulates, for example, was fine 30 years ago but they haven't changed their approach to it so they're possibly not regulating for the best result for the environment at the moment."

(Interview: Employee of salmon producer (PROD 02); June 2018)

Text Box 3

Some producers felt that regulatory compliance focussed too heavily on benthic impacts, and thus failed to assess or monitor the overall environmental impact or sustainability of the Scottish salmon industry. Issues such as the carbon footprint of farming operations and overall company logistics, as well as food packaging waste were also considered to be important environmental impact indicators by a number of producers, yet none are 
currently considered by SEPA or other regulatory bodies. Despite these perceived short fallings of the regulatory framework, several producers noted their optimism for the review and revision of salmon farming regulation taking place in Scotland at the time of this research.

\subsection{Beyond compliance}

\subsubsection{Stakeholder perception of beyond compliance in salmon aquaculture}

All participants were asked what beyond compliance meant to them in the context of the Scottish salmon industry. One stakeholder noted that compared to other sectors, beyond compliance is particularly challenging for the salmon aquaculture industry, given the heterogeneous nature of both the marine environment and salmon farming practices (Text Box 4)

"Beyond compliance is not as straightforward a concept for salmon farming as it is for discharges from a chimney, or recycling, or landfill, or one of the other sectors that is regulated by SEPA."

(Interview: Industry body (IND 01); July 2018)

Text Box 4

However, unanimously, participants agreed that beyond compliance meant exceeding baseline regulation in some form. Based on the responses obtained, beyond compliance was seen in two different and distinct ways:

1. Simply exceeding baseline compliance (i.e. seeking to achieve better environmental standards than regulation requires as a minimum); or

2. Taking measures that contribute to the overall sustainability of a company's operations but that are not regulated.

Specific examples of what beyond compliance could mean with regard to exceeding baseline compliance included: a reduction in sea lice chemicals, use of cleaner fish and use of new modelling tools, all of which could contribute to meeting (and doing better than) environmental quality standards (EQS) currently regulated within the industry. Importantly, some respondents who viewed beyond compliance in this way questioned that 
if the basic expectation of the industry became exceeding baseline environmental compliance, then the meaning and value of compliance would change and become more prescriptive.

Of those respondents who believed beyond compliance to mean more than just exceeding baseline regulation, a much broader and ambitious view was given of the industry (Text Box 6).

"It means thinking far wider than current concerns: ecological footprint of feed, energy use etc. It might also mean completely reassessing the vision of the industry."

(Online questionnaire: Regulator / Licensing Body (REG 03); June 2018)

"Active demonstrable and on-going management across the scope of its activities to maintain acceptable environmental and stakeholder impact thresholds; whether the thresholds are prescribed, prescribed but no longer fit for purpose or not prescribed at all. It's not about exceeding this or that regulatory criterion - it's about stewardship of a complex shared public space."

(Online questionnaire: Regulator / Licensing Body (REG 02); June 2018)

"... and then the beyond compliance is that there is a margin between you easily exceed the EQS criteria and then you go further and do things like habitat enhancement or increased recycling or voluntarily reduce $\mathrm{CO}_{2}$ footprints."

(Interview: Employee of salmon producer (PROD 02); June 2018)

Text Box 6

In these cases, the examples of what beyond compliance could look like were more varied and often looked beyond sea cage impacts. Examples included: reducing overall company carbon footprint, reduced use of polystyrene boxes, improved food packaging and use of more sustainable feeds.

\subsubsection{The need for beyond compliance in salmon aquaculture?}

There was unanimous agreement across all respondents that the industry needed to go beyond compliance, the reasons for which were twofold. Firstly, some respondents felt that existing compliance levels themselves were not satisfactory and thus more needed to be done to safeguard the sustainable future of the Scottish environment and industry. Two regulators agreed with this view (Text Box 7). 
"For Scotland to achieve 'One Planet Prosperity'... all businesses will need to go beyond compliance, and / or, compliance needs to be far more stringent."

(Online questionnaire: Regulator / Licensing Body (REG 03); June 2018)

"Yes... compliance with current regulation is clearly not satisfactory as the ECLLR/ REC Committee inquiries show. Consenting is not the industry's fault and in this respect, industry growth and associated acceptability must go hand in hand with an enabling and effective consenting framework."

(Online questionnaire: Regulator / Licensing Body (REG 02); June 2018)

\section{Text Box 7}

Secondly, many respondents felt that beyond compliance was necessary as it was aspirational, morally the right thing to do, and linked to this, could have positive implications for the public image and social licence of the industry (Text Box 8).

"It's aspirational and I think that's where modern businesses should be and that's where [we] want to be."

(Interview: Employee of salmon producer (PROD 02); June 2018)

"There is so much opposition to the industry at times I think the industry needs to be proactive... taking that extra step, showing the industry is responsible, environmentally aware and is aspiring to do things better - I think is a good message to put out there."

(Interview: Employee of salmon producer (PROD 01); June 2018)

Text Box 8

\subsubsection{Size of company and beyond compliance}

When asked if the size of a company could affect its ability to go beyond compliance, opinions of respondents were divided. Some felt that the size of a company should not affect its ability but instead could affect the ways or forms in which beyond compliance was realised. The size of a company was seen to influence the way in which it operated and potentially impacted the environment and thus the practices or measures it could take to rectify this or go beyond compliance (Text Box 9). 
"No - it is about the culture of an organisation in addressing the scope of its real and potential effects, transparently and to the best of its ability. Not size related."

(Online questionnaire: Regulator / Licensing Body (REG 02); June 2018)

"Not necessarily no... The advantage of a small company is, perhaps, I can't speak for everybody, but you've got a smaller team of people that are perhaps more passionate and care about what they are doing and are more involved in the whole business."

(Interview: Employee of salmon producer (PROD 03); June 2018)

Text Box 9

Conversely, some respondents believed the size of a company to be limiting in terms of beyond compliance. Availability of finance was seen as a potentially limiting factor to smaller companies and an advantage to larger ones. However, some respondents felt that this in itself should not necessarily prohibit beyond compliance in smaller companies but again give rise to different approaches across the industry (Text Box 10).

"Generally speaking, the larger the company, the more profits they have available to utilise in relation to greater environmental improvements."

(Interview: Employee of salmon producer (PROD 04); June 2018)

"There is no doubt that [a large fish farming company] appear to be at the forefront of providing better information to planning authorities and engaging in the long term monitoring discussion. Much less positive engagement with the smaller companies."

(Online questionnaire: Regulator / Licensing Body (REG 01); June 2018)

"It's not necessarily all financially resourced based... The big guys have got the finance to develop expensive equipment and trial things, where perhaps we couldn't fund that kind of thing."

(Interview: Employee of salmon producer (PROD 05); June 2018)

Text Box 10

\subsubsection{Existing examples of beyond compliance}

All producers felt that their respective companies were already implementing measures that to them constituted beyond compliance, but they might not necessarily have called it 'beyond compliance' as this is a relatively new term to the industry. Furthermore, although beyond compliance was already taking place across the industry, some respondents felt 
that it was not widely acknowledged or publicised at present due to challenges in effectively demonstrating it (Text Box 11).

"In many areas we do. If you look at our lice control, our mortality reporting or even our annual report, we exceed compliance regularly in that."

(Interview: Employee of salmon producer (PROD 02); June 2018)

"I believe that we already are beyond compliance but it's demonstrating that is the challenge - that's the big issue for us."

(Interview: Industry body (PROD 01); July 2018)

Text Box 11

Many producers cited their use of cleaner fish as a form of beyond compliance due to the resulting reduction in the use of chemical or medical treatments entering the marine environment. However, conversely, one regulator used cleaner fish as an example of the industry being poor stewards of the environment in which they operate due to the argued depletion of the Ballan wrasse population (Text Box 12). This highlights the issue of implementing measures at a farm level, which have a positive affect at that scale, but may have unintended consequences at the broader, ecosystem scale.

“... it's less a compliance issue, but more the approach and response by industry to matters of sustainable or acceptable practice on issues that arise that are not part of any set of regulatory compliance criteria - of which there are many in a complex marine farming environment. One example would be the industry's disappointing approach to the harvesting of wild wrasse for its own use."

(Online questionnaire: Regulator / Licensing Body (REG 02); June 2018)

Text Box 12

Other examples given of beyond compliance related more to the global environmental impact of companies rather than local or seabed related issues that are currently regulated (Text Box 13).

"But you know [our company] does all that in excess. We have a carbon reduction programme for our operations, we have a kind of logistics improvement programme for reducing emissions and packaging and plastics. We already do that, with or without a regulator."

(Interview: Employee of salmon producer (PROD 02); June 2018)

"We are looking at our air freight boxes at the moment which currently are polystyrene and we'd like them not to be so we're looking at alternative products."

(Interview: Employee of salmon producer (PROD 05); June 2018)

Text Box 13 
All producers were subscribed to a variety of third party certification or audit schemes including ASC, Freedom Foods, Global GAP (Good Aquaculture Practice), RSPCA Assured and ISO14001, amongst others. There was a sense from producers that subscription to such schemes was fundamentally voluntary, but many were also requirements of the consumer market, contributing to social licence and the overall marketability of their products (Text Box 14).

"They give a certain element of comfort and control to the retailers specifically". (Interview: Industry body (IND 01); July 2018)

\section{Text Box 14}

All supermarket respondents stated that they had mandatory standards for their salmon producers to achieve, demonstrated by subscription to third party certification schemes, and in some instances, adherence to their own in-house sourcing or sustainability policies. Furthermore, all supermarkets expressed some level of willingness to support innovation and development of the industry, and acknowledged that supermarkets hold a role in changing the negative public and media image of Scottish salmon farming.

\subsubsection{Relationship between existing regulation and beyond compliance}

Despite the general consensus for the need of the industry to go beyond compliance, many respondents voiced concerns about the relationship between the current compliance thresholds and moving beyond these. With a regulatory regime that is perceived by many to be unfit for purpose and an industry that is not yet fully compliant, many respondents felt that these issues had to be resolved before beyond compliance could be truly pursued (Text Box 15).

"Surely compliance in itself should be our first aim because the industry as a whole isn't $100 \%$ compliant... so that is the first stage we need to meet. I think we need to be able to meet that through a ... change in regulation."

(Interview: Employee of salmon producer (PROD 01); June 2018)

Text Box 15 
There was also a sense, specifically amongst producers, that SEPA's push for beyond compliance was premature and that issues surrounding the current regulatory regime needed to be resolved in the first instance. At a time when the industry and its regulators were under intense scrutiny, many felt that SEPA should be prioritising a review of existing regulation from which the industry could more easily or clearly achieve compliance. Without a sound foundation to work from, many saw beyond compliance as meaningless (Text Box 16).

"It has to be grounded in reality. I think the focus needs to be in getting the existing legislative framework right first and then that will create the conditions for moving to beyond compliance. Unless they get the basics right first, there's no point in talking about beyond compliance. It's a step by step process."

(Interview: Employee of salmon producer (PROD 01); June 2018)

"Regulation in many areas is not fit for purpose and rather than fix that first and then move to a sphere of beyond compliance, they have jumped one step. And they may or may not be criticised for that going forward."

(Interview: Employee of salmon producer (PROD 02); June 2018)

\section{Text Box 16}

Although the producers placed the responsibility for updating environmental regulation with SEPA, one regulator and many of the supermarkets gave the impression that they saw beyond compliance as an opportunity for the industry to influence regulation. From this perspective, respondents saw beyond compliance as representing industry best practice from which regulation could be developed.

\subsubsection{Incentives and motivations}

Although the producers believed they were already going beyond compliance in many areas of their operations, possible incentives and motivations for doing so were discussed. These were split between three key areas: improvements to regulation and licencing; social licence; and brand image / profit. One respondent discussed how improvements to the regulatory and licencing framework that rewarded beyond compliant applications could incentivise companies to improve their performance (Text Box 17). 


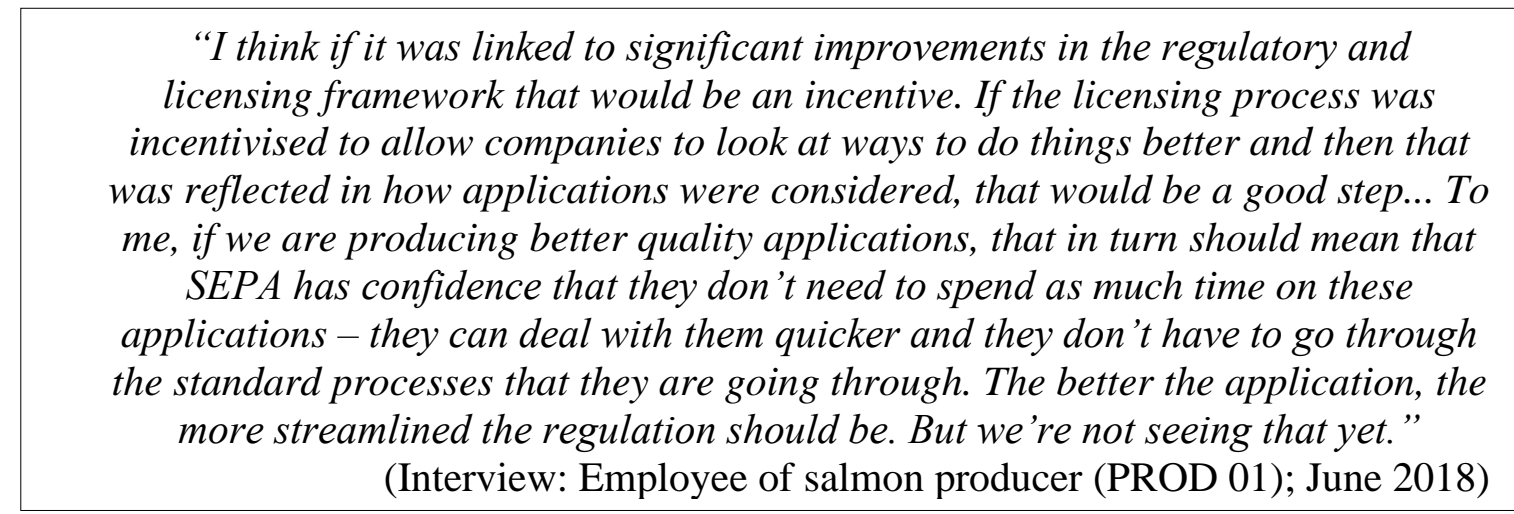

Text Box 17

A number of respondents voiced optimism that beyond compliance could result in improved public perception and media relations. This was seen as both a reason why the industry needed to go beyond compliance, as well as an incentive for doing so (Text Box $18)$.

"My own personal opinion is that if we go beyond compliance, we may then receive less negative press and less negativity from NGOs."

(Interview: Employee of salmon producer (PROD 04); June 2018)

Text Box 18

Lastly, motivations linked to company brand, market reputation and ultimately, profit were raised (Text Box 19).

"I kind of think we probably already have [the incentive] internally, in that it's our brand... We are a brand, we're sold by name... That name and that brand is really, really important and what we do to make people want to come back and buy it... that's probably our biggest driver. So it's ultimately the customer, the outside perception of what we do. We need to be completely integral to that."

(Interview: Employee of salmon producer (PROD 05); June 2018)

"At a company level I think going beyond compliance probably means better prospects for selling our product to more varied customers, which will ultimately improve performance so yeah, better profits."

(Interview: Employee of salmon producer (PROD 04); June 2018)

Text Box 19

From the results, incentives for going beyond compliance can be seen to fall into two categories: direct and indirect. Direct incentives appear to be more applicable at the farm level and include examples such as a reduction in licence processing times for beyond 
compliant applications. Alternatively, indirect incentives applied more to overall company operations and practices and included motivations such as improved public perception and product sales. 


\section{Discussion}

\subsection{Regulation and beyond compliance}

Whilst the Scottish salmon industry is strictly regulated, the consensus - both from this research and in the wider discourse about the sector - is that the regulatory framework is fragmented, out dated and inefficient and thus requires revision to better serve the modern industry and marine environment (Scottish Government, 2010; Tett et al, 2018). Largely founded on policy designed for land based developments and point source pollution discharges to freshwater environments (Peel and Lloyd, 2008), both the Scottish planning and environmental licencing frameworks that serve the salmon industry could benefit from a more management focussed regime, giving cognisance to the unpredictability of the marine environment that is not seen in land based developments. "Streamlining" of regulation was also commonly discussed throughout this research, calling for consolidation of the number of responsible bodies and overlap of information required. In addition, levels of whole industry compliance dropped "during 2017 to $81.14 \%$, against a relative peak of $85.75 \%$ in 2016" (SEPA, 2018), suggesting there is still progress to be made in attaining baseline compliance for existing regulatory requirements. For beyond compliance to be truly embraced by the industry, it is likely that the issues pertaining to the regulatory framework will need to be resolved first.

Based on the opinions gathered during this research, it is apparent that producers feel the responsibility for the revision of industry regulation largely sits with SEPA. However, the industry has a role in influencing the future of regulation. An example of this is the evolution of Farm Management Agreements (FMAs), which began as voluntary agreements over farm management practices within shared water bodies, and have now been made obligatory through the Scotland Fisheries and Aquaculture Act (Carter, 2018). This is a prime example of beyond compliance in the Scottish salmon industry informing legislative change for the overall benefit of the sector and wider environment. As such, aquaculture producers should use any period of review and change as an opportunity to be proactive and vocal in paving the way for more efficient regulation that better serves their industry. 
An observed weakness of the current regulatory framework is the limited amount of post consent monitoring, resulting in uncertainties and knowledge gaps surrounding the environmental impact of marine cage sites. This could be resolved by producers carrying out additional monitoring of their sites and improved modelling approaches such as the use of large scale hydrodynamic models; ground truthing the predictions of past modelling; generating more data to be used in future modelling; and giving more certainty to the outcomes of such modelling. Any additional monitoring and environmental evidence that companies can generate will lead to a better understanding of the marine environment and help to identify better locations for future growth, or where reduced production is required. This is a short term beyond compliance action that could initially be taken by all companies to benefit both themselves and the regulators.

\subsection{What could beyond compliance look like?}

The Scottish salmon industry has already taken many steps that could be seen to constitute beyond compliance, with or without influence from regulators (Table 3). The Code of Good Practice (2015) is an example of a cross-industry initiative to go beyond compliance, encouraging companies to operate sustainably. However, all stakeholders recognised a need to do more, to both safeguard the marine environment and to guarantee the social licence that the industry needs to expand and thrive. At present, the motivation for beyond compliance appears twofold. On the one hand, salmon producers see it as a way of adding value to their company brand and overall positive image of the industry, which fundamentally benefits their financial bottom line. However, there is also a sense of moral obligation and stewardship for the marine environment in which they operate and heavily depend upon.

\section{*INSERT TABLE 3 HERE*}

From the results, existing and future beyond compliance measures are also twofold: achieving and exceeding baseline environmental compliance (i.e. minimising benthic impacts) or taking measures that are not regulated at all (i.e. reducing company carbon 
footprint). Both are important and reduce environmental pressures on local and global scales respectively. With access to an ever growing global market and Scottish salmon production set to increase, issues such as increased greenhouse gas emissions from air freight (Schlag, 2010) are likely to make a greater contribution to the overall environmental impact of the sector in the future. Such global considerations sit firmly outside SEPA's remit as a Scottish environmental regulator, questioning how such measures could and should be regulated. To some extent certification schemes such a GlobalGAP and ASC already achieve this, but given the variance of subscription across the industry, and the different indicators used by each scheme (Amundsen and Osmundsen, 2018), this does not give a consistent approach to tackling global environmental challenges.

At a more local scale, a revised regulatory scheme could encourage new and radical approaches in Scotland to address some of the environmental and biological issues. In Norway, this is facilitated through 'green' licences that allow companies to develop innovative green technologies such as closed containment systems (CCS), land-based production and offshore systems (Fløysand and Jakobsen, 2017) offering potential solutions to sea lice, waste discharge and fish escape issues during on growing stages at sea. However, such technology is likely to be limited in use to larger companies, due to required levels of investment and associated risk.

The ways in which producers are currently going beyond compliance is varied, and this variance could possibly increase in the future due to differences in company size, management and structure, as well as advancements in technology and related market availability. However, one way to level the playing field amongst companies and collectively address environmental challenges, could be to implement an initiative similar to the Monitor Farm programme used in the Scottish agriculture industry (Monitor Farm Scotland, 2017). Aimed at improving "the profitability, productivity and sustainability of producers" the programme uses a group of 'monitor farms' covering different geographies, farming types and challenges, and involves "practical demonstrations, the sharing of best practice and the discussion of up-to-date issues" to improve "agricultural efficiency, environmental management and mitigating climate change" (Monitor Farm Scotland, 2017). A similar initiative could be effective for the Scottish salmon industry, encouraging 
knowledge exchange on pre-competitive areas and facilitating the trial of innovative new technologies. Collection of long-term in-situ environmental data at such locations would also help monitor changes in the environmental conditions and assist planning and adaptation to risks and pressures from climate change.

Implementing a system of beyond compliance for salmon aquaculture requires demonstration of success or quantification of its benefits. This is a challenge and has resulted in little industry promotion of beyond compliance measures to date. Arguably, the third-party certification schemes provide a form of measurement and assurance of beyond compliance. However, they do not always cover the scope of beyond compliance measures relevant to the Scottish industry and its environment. Consequently, current contributions and successes made to reducing the environmental impact of the salmon farming industry is dependent on reporting by individual companies or by compliance with their respective and differing third party certification schemes. Such measures do not allow for accurate comparison between companies or an overall indication of industry performance, due to differences in reporting method or compliance requirements. Based on the current regulatory framework, there is no way to meaningfully quantify beyond compliance measures such as a reduction in polystyrene boxes or company carbon emissions.

Again, looking to other sectors for examples of beyond compliance and their quantification, the building industry could provide a suitable template. BREEAM (Building Research Establishment Environmental Assessment Method) is a third party certification assessment that "recognises and reflects the value of higher performing assets across the built environment lifecycle" (Building Research Establishment, 2018). A form of beyond compliance, BREEAM supports developers to design and operate buildings that are more sustainable than simply compliant with baseline building regulation. The sustainability of each project is measured according to a range of categories including energy, innovation, materials, management and waste, which themselves are then broken down into "assessment issues, each with its own aim, target and benchmarks" (BREEAM, 2018). The overall BREEAM ratings range from 'pass' to 'outstanding' (Table 4), allowing clients or stakeholders to compare building performance between different BREEAM buildings, as well as between BREEAM and non-BREEAM buildings (BREEAM, 2018). 
*INSERT TABLE 4 HERE.*

Thus, for beyond compliance to influence the industry, have greatest impact on Scotland's overall ecological footprint and to be accepted as an integral tool for improved sustainability, a universal measurement system such as BREEAM is required. Quantifiable measures for beyond compliance would make it objective and comparative, leading to consistent implementation.

Based on the two tiers of beyond compliance measures - local and global - it is possible that different bodies should be responsible for each (see Table 5 for example). SEPA's involvement in the regulation of local environmental impacts possibly makes them most suitable to deal with beyond compliance at the farm scale, with support from other regulatory bodies where required. Global level measures are harder to allocate and arguably should stand alone from environmental regulation. Industry wide collaboration, along with a representative organisation, such as SSPO, could develop a Scotland specific beyond compliance scheme, focussing on best practice measures to minimise and mitigate wider environmental impacts in a way that is quantifiable and comparable. However, to be fully successful, this would require commitment from all salmon producers operating in Scotland.

\section{*INSERT TABLE 5 HERE*}

Again, the ways in which beyond compliance might be incentivised at these two scales could differ and are likely to be direct or indirect. If SEPA and other regulators were to take responsibility for the local scale, direct incentives such as reduced processing times for beyond compliant applications or increased permitted biomass for farms that continually achieve better than EQS compliance could be effective. Such direct incentives would need to be decided on a site-by-site basis, based on individual merit. Whilst at the global scale, indirect incentives such as positive public and media perception due to improved overall environmental performance - potentially resulting in improved product sales and thus profit - would likely be the driving force for most companies 


\section{Conclusions and recommendations}

Beyond compliance is already happening in many forms across the Scottish salmon industry, largely without encouragement from regulators. There appears to be two geographical scales of beyond compliance to reduce environmental impacts, both of which are important in their own right. Firstly, beyond compliance at the farm level which tends to be limited to bettering EQS set by current environmental regulation. Importantly, these measures have little impact on global resource use and their benefit is greatest at a local, ecosystem level. Secondly, the overall company measures that contribute to tackling global issues such as climate change and over use of resources. Such measures are not currently regulated in the Scottish salmon industry, but third party certification schemes go some way to achieving this.

Initiatives similar to the Monitor Farm programme and BREEAM could straddle both tiers of beyond compliance, thus encompassing both local and global environmental improvements. Specific to Scotland's own industry challenges, such schemes could be tailored to the carrying capacity of the Scottish marine environment, and thus find the appropriate balance between physical, production, ecological and social dimensions (Ross et al., 2013) whilst also considering the global environmental issues at play. Development of such schemes would require collaboration from all industry stakeholders including producers, SEPA, other regulators, supermarkets, industry bodies, researchers and scientists, Government and possibly, the media and public. Further, based on the two identified tiers of beyond compliance, there could be a need for different auditing bodies to cover all aspects of the two tiers effectively.

Salmon farming is an important industry for rural communities in Scotland and its environmental impact and overall sustainability is critical at both local and global scale. The future of the Scottish salmon industry is promising but requires a broader environmental stewardship approach and improved collaboration from all stakeholders to ensure its long-term success in what is a heterogeneous environment, regulatory regime and industry. Consequently, beyond compliance initiatives will be an integral part of this at both scales. 


\section{Acknowledgements}

The authors would like to thank all of the stakeholders that participated in this research.

This work has been partly supported by the Tools for Assessment and Planning of

Aquaculture Sustainability (TAPAS) project which has received funding from the EU H2020 research and innovation programme under Grant Agreement No 678396. 


\section{References}

Amberg, S.M. and Hall, T.E. (2008), Communicating risks and benefits of aquaculture: a content analysis of US newspaper representations of farmed salmon. Journal of World Aquaculture Society, 39, 143 - 157.

Amundsen, V.S. and Osmundsen, T.C. (2018), Sustainability indicators for salmon aquaculture. Data in Brief, 20: 20-29.

Borck, J. C. and Coglianese, C. (2011), Beyond compliance: explaining business participation in voluntary environmental programs, in Parker, C. and V. L. Nielsen (eds.), Explaining Compliance: Business Responses to Regulation. Edward Elgar Publishing Limited, Cheltenham.

Building Research Establishment (2018), BREEAM. Accessed 12.07.2018 via https://www.breeam.com

Busch, L. (2000) The moral economy of grades and standards. Journal of Rural Studies, 16: 273-283.

Busch, L. and Bowker, G.C. (2011), Standards: Recipes for reality. MIT Press, Cambridge, MA, USA. 390pp.

Carter, C. (2018), The Politics of Aquaculture: Sustainability Interdependence, Territory and Regulation in Fish Farming. Routledge, Oxon.

Ellis, T. et al., (2016), Trends during development of Scottish salmon farming: An example of sustainable intensification?, Aquaculture 458, pp. 82 - 99.

Environment, Climate Change and Land Reform Committee (ECCLR) (2018), Environmental Impacts of Salmon Farming. Accessed 10.07.2018 via http://www.parliament.scot/parliamentarybusiness/CurrentCommittees/107588.aspx

FAO Fisheries and Aquaculture Technical Paper. No. 527. Rome, FAO. 2009. 57p, Environmental impact assessment and monitoring in aquaculture. Includes a CD-ROM containing the full document (648 pages).

Fish Farming Expert (6 $6^{\text {th }}$ July 2018), Scotland's first salmon farming visitor centre planned for Skye. Accessed 18.07.2018 via https://www.fishfarmingexpert.com/article/scotlandsfirst-salmon-farming-visitor-centre-planned-for-skye/

Fløysand, A. and Jakobsen, S.E. (2017), Industrial renewal: narratives in play in the development of green technologies in the Norwegian salmon farming industry. The Geographical Journal, 183(2): 140-151.

Flynn, A., Hacking, N. (2019) Setting standards for a circular economy: a challenge too far for neoliberal environmental governance? Journal of Cleaner Production, 212: 12561267. 
Global Footprint Network (2018), Global Footprint Network: Advancing the Science of Sustainability. Accessed 26.07.2018 via https://www.footprintnetwork.org

Gunningham, N., Kagan, R. A. and Thornton, D. (2006), Social License and

Environmental Protection: Why Businesses Go Beyond Compliance. In Law and Social Inquiry, Volume 29, Issue 2. DOI: https://doi.org/10.1111/j.1747-4469.2004.tb00338.x

Heumer, L. Corporate social responsibility and multinational corporation identity: Norwegian strategies in the Chilean Aquaculture Industry. Journal of Business Ethics, 91(2): 265-277.

Hynes, S., Skoland, K., Ravagnan, E., Gjerstad, B. and Krøvel, A.V. (2018), Public attitudes toward aquaculture: An Irish and Norwegian comparative study. Marine Policy, 96: $1-8$.

Knapp, G. and Rubino, M.C. (2016), The political economics of marine aquaculture in the United States. Reviews in Fisheries Science \& Aquaculture, 24(3): 213-229.

Lee, M.H.W., Clark, A., Rupp, J., Wietelman, D.C., Graham, J.D. 2019. Public opinion toward hydraulic fracturing: The effect of beyond compliance and voluntary third-part certification. Energy Policy, 128: 306-315.

Marine Scotland Science (2018), Scottish Fish Farm Production Survey 2017. Edinburgh: The Scottish Government

Marks and Spencer (2018), Rural Economy and Connectivity Committee, Salmon Farming in Scotland: Submission from Marks and Spencer PLC. Accessed 10.07.2018 via http://www.parliament.scot/parliamentarybusiness/CurrentCommittees/107585.aspx

Matthews, B. and Ross, L. (2010), Research Methods: A practical guide for social science. Pearson Education Limited, Edinburgh.

Monitor Farm Scotland (2017), Monitor Farm Scotland: About Us. Accessed 11.07.2018 via http://www.monitorfarms.co.uk/hub/about-us

Olsen, M. S. and Osmundsen, T. C. (2017), Media framing of aquaculture. Marine Policy, $76,19-27$.

Peel, D. and Lloyd, M.G. (2008), Governance and planning policy in the marine environment: regulating aquaculture in Scotland. The Geographical Journal, 174(4): 361373.

Pieniak, Z., Vanhonacker, F. and Verbeke, W. (2013), Consumer knowledge and use of information about fish and aquaculture. Food Policy, 40: 25-30.

Porter, M. 1991. America's green strategy. Scientific American, 264(4): 96.

Robson, C. and McCartan, K. (2016), Real World Research, $4^{\text {th }}$ Edition, John Wiley \& Sons Ltd, Chichester. 
Ross, L.G., T. C. Telfer, L. Falconer, D. Soto and Aguilar-Manjarrez, J. (eds) (2013), Site selection and carrying capacities for inland and coastal aquaculture. FAO/Institute of Aquaculture, University of Stirling, Expert Workshop, 6-8 December 2010. FAO Fish Aquacult Proc 21. FAO, Rome

Rural Economy and Connectivity Committee (REC) (2018), Salmon Farming in Scotland. Accessed 10.07.2018 via http://www.parliament.scot/parliamentarybusiness/CurrentCommittees/107585.aspx

Salgado, H., J. Bailey, R. Tiller and Ellis, J. (2015), Stakeholder perceptions of the impacts from salmon aquaculture in the Chilean Patagonia. Ocean and Coastal Management, 118, $189-204$.

Tett, P., Benjamins, S., Coulson, M., Davidson, K., Fernandes, T., Fox, C., Hicks, N., Hunter, D.C., Nickell, T., Risch, D. and Tocher, D. (2018), Review of the Environmental Impacts of Salmon Farming in Scotland. Report for the Environment, Climate Change and Land Reform (ECCLR) Committee. Report, Scottish Parliament. Accessed 09.07.2018 via http://www.parliament.scot/S5_Environment/General\%20Documents/20180125_SAMS_R eview_of_Environmental_Impact_of_Salmon_Farming_-_Report.pdf

Schlag, A. K. (2010), Aquaculture: an emerging issue for public concern. Journal of Risk Research, 13:7, 829 844, DOI: 10.1080/13669871003660742

Scotland Food and Drink (2016), Aquaculture Growth to 2030: A Strategic Plan for farming Scotland's seas. Accessed 01.05.2018 via http://scottishsalmon.co.uk/wpcontent/uploads/2016/10/aquaculture-growth-to-2030.pdf

Scottish Government (2010), Delivering Planning Reform for Aquaculture. Edinburgh: Scottish Government.

Scottish Government (2018), Scotland's 10 Year Farmed Fish Health Framework. Accessed via http://www.gov.scot/Resource/0053/00535697.pdf

Scottish Salmon Producers Organisation (SSPO) (2015), Code of Good Practice. Accessed 19.06.2018 via http://scottishsalmon.co.uk/cogp/

Scottish Sea Farms, Marine Harvest, Grieg Seafood, Wester Ross Salmon, Cooke Aquaculture Scotland, Loch Duart and The Scottish Salmon Company (2018), Report Versus Reality: A pocket guide to Scottish salmon farming. Accessed 20.06.2018 via https://www.scottishseafarms.com/media/1553/reported-versus-reality.pdf

SEPA (2016), One Planet Prosperity - Our Regulatory Strategy. Accessed 02.05.2018 via https://www.sepa.org.uk/media/219427/one-planet-prosperity-our-regulatory-strategy.pdf

SEPA (March 2017), Delivering One Planet Prosperity - our Sector Plan approach. Accessed 10.07.2018 via https://www.sepaview.com/2017/03/our-sector-plan-approach/

SEPA (October, 2018), Environmental compliance of Scottish business exceeds $90 \%$ for third year in a row. Accessed 18.10.2018 http://media.sepa.org.uk/media- 
releases/2018/environmental-compliance-of-scottish-business-exceeds-90-for-third-yearin-a-row/

Shepherd, C.J., and Little, D.C. (2014), Aquaculture: are the criticisms justified? II Aquaculture's environmental impact and use of resources, with special reference to farming Atlantic salmon. World Agric. 4 (2), 37 - 52

Vince, J. and Haward, M. (2017), Hybrid governance of aquaculture: opportunities and challenges. Journal of Environmental Management, 201: 138-144.

Whitmarsh, D. and Palmieri, M.G. (2011), Consumer behaviour and environmental preferences: a case study of Scottish salmon aquaculture. Aquaculture Research, 42, 142 147 
Table 1: Summary of research participants.

\begin{tabular}{|l|c|c|l|l|}
\hline Participant group & $\begin{array}{l}\text { Number of } \\
\text { participants }\end{array}$ & $\begin{array}{c}\text { Number } \\
\text { contacted }\end{array}$ & Approach used & Code \\
\hline $\begin{array}{l}\text { Salmon producers: } \\
\text { Employees responsible } \\
\text { for environmental } \\
\text { compliance }\end{array}$ & 6 & 12 & $\begin{array}{l}\text { Semi-structured } \\
\text { interview (face-to-face } \\
\text { or via telephone) }\end{array}$ & PROD \\
\hline $\begin{array}{l}\text { Regulators and } \\
\text { licensing bodies }\end{array}$ & 4 & 6 & Online questionnaire & REG \\
\hline $\begin{array}{l}\text { Supermarkets: Fishery } \\
\text { and Seafood Managers }\end{array}$ & 3 & 9 & Online questionnaire & SUPER \\
\hline \begin{tabular}{l} 
Industry bodies \\
\hline
\end{tabular} & 1 & 2 & $\begin{array}{l}\text { Semi-structured } \\
\text { interview (via telephone) }\end{array}$ & IND \\
\hline
\end{tabular}


Table 2: Summary of most common challenges identified by respondents.

\begin{tabular}{|l|l|}
\hline Key theme & Examples of perceived challenges \\
\hline Regulation and Planning & $\begin{array}{l}\text { Difficulties in finding new sites to support expansion; } \\
\text { fragmentation of current regulatory framework; regulation 'not } \\
\text { fit for purpose' }\end{array}$ \\
\hline Biological & Sea lice; gill disease; general health and disease challenges \\
\hline Social & $\begin{array}{l}\text { Social licence to operate; poor media representation and public } \\
\text { perception }\end{array}$ \\
\hline Sustainability & Co-existence with wild fishery interests; medication use \\
\hline
\end{tabular}


Table 3: Examples of beyond compliance in the Scottish salmon industry.

\begin{tabular}{|l|l|}
\hline Example of Beyond Compliance & Industry Stakeholder(s) Responsible \\
\hline $\begin{array}{l}\text { Scotland's 10 Year Farmed Fish } \\
\text { Health Framework (2018) }\end{array}$ & $\begin{array}{l}\text { The Farmed Fish Working Group - a } \\
\text { collaborative body including members from } \\
\text { finfish farming businesses, trade } \\
\text { associations/networks, the Scottish Aquaculture } \\
\text { Innovation Centre and veterinary professionals, } \\
\text { as well as regulatory and advisory bodies }\end{array}$ \\
\hline $\begin{array}{l}\text { Reported versus Reality: A pocket } \\
\text { guide to Scottish salmon farming } \\
\text { (2018) }\end{array}$ & $\begin{array}{l}\text { Collaboration between seven Scottish salmon } \\
\text { producers }\end{array}$ \\
\hline $\begin{array}{l}\text { Publication of sea lice data on a farm } \\
\text { by farm basis }\end{array}$ & $\begin{array}{l}\text { Scottish Salmon Producers Organisation (SSPO) } \\
\text { and their members }\end{array}$ \\
\hline $\begin{array}{l}\text { Construction of a visitor centre to } \\
\text { allow the public to learn more about } \\
\text { Scottish salmon farming }\end{array}$ & A large Scottish salmon producer \\
\hline $\begin{array}{l}\text { In-house sourcing or sustainability } \\
\text { policies for seafood products }\end{array}$ & British supermarkets \\
\hline Code of Good Practice & $\begin{array}{l}\text { Scottish Salmon Producers Organisation (SSPO) } \\
\text { and their members }\end{array}$ \\
\hline
\end{tabular}

${ }^{1}$ Scottish Government (May 2018). ${ }^{2}$ Scottish Sea Farms, Marine Harvest, Grieg Seafood, Wester Ross Salmon, Cooke Aquaculture Scotland, Loch Duart and The Scottish Salmon Company (2018). ${ }^{3}$ Fish Farming Expert (2018). 
Table 4: Summary of BREEAM ratings are performance equivalent.

1

\begin{tabular}{|l|l|}
\hline BREEAM Rating & Performance equivalent \\
\hline Outstanding & Less than top 1\% of UK new non-domestic buildings (innovator) \\
\hline Excellent & Top 10\% of UK non-domestic buildings (best practice) \\
\hline Very good & Top 25\% of UK non-domestic buildings (advanced good practice) \\
\hline Good & Top 50\% of UK non-domestic buildings (intermediate good practice) \\
\hline Pass & Top 75\% of UK non-domestic buildings (standard good practice) \\
\hline
\end{tabular}


Table 5: Summary of what 'could' beyond compliance look like for the Scottish salmon industry

\begin{tabular}{|c|c|c|c|c|}
\hline $\begin{array}{l}\text { Type of beyond } \\
\text { compliance }\end{array}$ & $\begin{array}{l}\text { Scale of } \\
\text { impact }\end{array}$ & Examples & Responsibility? & Incentives \\
\hline $\begin{array}{l}\text { 1. Bettering } \\
\text { baseline } \\
\text { compliance / } \\
\text { regulation }\end{array}$ & $\begin{array}{l}\text { Local / farm } \\
\text { (i.e. benthic } \\
\text { environment) }\end{array}$ & $\begin{array}{l}\text { Better SEPA's } \\
\text { EQS due to } \\
\text { improved feed } \\
\text { technology, } \\
\text { reduced } \\
\text { medication and } \\
\text { use of cleaner } \\
\text { fish }\end{array}$ & $\begin{array}{l}\text { SEPA (with } \\
\text { support from } \\
\text { other regulators } \\
\text { as required) }\end{array}$ & $\begin{array}{l}\text { Direct: } \\
\text { increased } \\
\text { biomass; } \\
\text { reduced } \\
\text { processing times } \\
\text { for licence } \\
\text { applications }\end{array}$ \\
\hline $\begin{array}{l}\text { 2. Measures that } \\
\text { contribute to } \\
\text { the overall } \\
\text { sustainability } \\
\text { of a } \\
\text { company's } \\
\text { operations } \\
\text { (but that are } \\
\text { not regulated) }\end{array}$ & $\begin{array}{l}\text { Global } \\
\text { (i.e. climate } \\
\text { change and } \\
\text { resource use) }\end{array}$ & $\begin{array}{l}\text { Reduction in } \\
\text { overall company } \\
\text { carbon footprint; } \\
\text { use of } \\
\text { sustainable } \\
\text { feeds; reduction } \\
\text { in use of } \\
\text { polystyrene } \\
\text { boxes }\end{array}$ & $\begin{array}{l}\text { Industry body } \\
\text { (e.g. SSPO or } \\
\text { newly formed } \\
\text { collaborative } \\
\text { body) }\end{array}$ & $\begin{array}{l}\text { Indirect: } \\
\text { improved public } \\
\text { and media } \\
\text { perception; } \\
\text { increased sales; } \\
\text { improved profits }\end{array}$ \\
\hline
\end{tabular}




\section{Appendix A - Semi structured interview questions}

1. How long have you worked in the Scottish salmon sector for?

2. Do you think the current regulatory system is effective and efficient and meets the needs of the industry? Yes / No. Give reasons why.

3. Do you think the industry is operating sustainably at present?

4. Do you think the industry can meet the projected 2030 growth targets whilst operating a 'business as usual' approach?

5. In your opinion, what are the 3 key challenges for the expansion of the industry in Scotland?

6. How effective do you consider environmental modelling to be?

7. Do you think environmental modelling holds an important role in the sustainable expansion of the industry?

8. What monitoring do you currently do? And do you think this is adequate?

9. How important do you consider the role of 3rd party certification schemes to be in the Scottish industry?

10. Is your company currently subscribed to any 3rd party schemes? If so, which ones?

11. Of the $3^{\text {rd }}$ party schemes you are subscribed to, how many of these are requirements of supermarkets / buyers / overseas markets and how many are voluntary?

12. What are your views on the transparency of data sharing in the industry? Do you think there is room for improvement, and if so, how?

13. Are you aware of SEPA's drive for 'beyond compliance'?

14. What does 'beyond compliance' mean to you in terms of the Scottish salmon industry?

15. Do you think the industry needs to go 'beyond compliance'? (Or do you think compliance with current regulation is satisfactory)?

16. What would be the biggest driving force for your company to go 'beyond compliance'? (e.g. the environment, fish health, community support, profit)

17. Do you think that emerging technologies such as RAS and CCS or moving sites further offshore have a place in the expansion of the industry?

18. Do you think the size of a company can affect its ability to go 'beyond compliance'?

19. Who do you think the responsibility for beyond compliance should sit with within the industry or your company?

20. Do you think beyond compliance could result in additional work load and responsibilities for farm managers?

21. Do you have any views on how 'beyond compliance' could be effectively quantified or measured? 


\section{Appendix B - Online questionnaire for regulators and licensing bodies}

1. Your name

2. Your organisation / company

3. What is your job title / role?

4. Do you think the current regulatory system is effective and efficient and meets the needs of the Scottish salmon industry? Please give reasons for your answer.

5. Do you think the Scottish salmon industry is operating sustainably at present? Please give reasons for your answer.

6. From the point of view of your own organisation and its role in the regulatory framework, what are the greatest non-compliance or non-conformity issues that you experience with the Scottish salmon industry at present?

7. Further to question 6 , is your organisation taking any steps to support the salmon industry in resolving these issues?

8. Do you think the Scottish salmon industry can meet the projected 2030 growth targets whilst operating a 'business as usual' approach? Please give reasons for your answer.

9. In your opinion, what are they 3 key challenges for the expansion of the salmon industry in Scotland?

10. Do you think the proposed expansion of the industry could present challenges for your organisation? Please give reasons for your answer.

11. How effective do you consider environmental modelling to be?

12. Do you think environmental modelling holds an important role in the sustainable expansion of the industry? And if so, how?

13. What does 'beyond compliance' mean to you in terms of the Scottish salmon industry?

14. Do you think the Scottish salmon industry needs to go beyond compliance? Or do you think compliance with current regulation is satisfactory? Please give reasons for your answer.

15. Do you think your organisation could have a role in supporting beyond compliance in the Scottish salmon industry? And if so, how?

16. Do you think regulators can incentivise salmon producers to go beyond compliance? For your regulatory body, what could this look like?

17. Do you think emerging technologies such as RAS and CCS or moving sites further offshore have a place in the expansion of the industry?

18. Do you think the size of a company can affect its ability to go beyond compliance?

19. Do you have any views on how beyond compliance could be effectively quantified or measured? 


\section{Appendix C - Online questionnaire for supermarkets}

1. Your name

2. Which supermarket do you work for?

3. What is your job title / role?

4. Does your supermarket sell Scottish farmed salmon products? Yes / No.

5. Are you farmed salmon products exclusively Scottish? Yes / No.

5a. If you answered yes, please give brief reasons why you only sell Scottish salmon?

6. Which Scottish salmon producers do you currently source from? Options included: Marine Harvest Scotland, Scottish Sea Farms, Scottish Salmon Company, Cooke Aquaculture, Loch Duart Ltd, Wester Ross Salmon, Greig Seafood Shetland, Kames Fish Farming Ltd, Other. 6a. If you selected 'other', please specify.

7. What mandatory standards do your Scottish salmon suppliers have to meet? Please list all applicable e.g. ASC, MSC, RSPCA Assured, Organic

8. Do you have your own 'in-house' sourcing or sustainability policy that applies to salmon products? Please provide brief details of what this covers or a link to further information.

9. What do you see as the three biggest challenges or barriers to the future growth of the Scottish salmon farming industry?

10. What does 'beyond compliance' mean to you in the context of the Scottish salmon farming industry?

11. What measures would you like to see your Scottish salmon suppliers taking that were beyond compliance?

12. Do you think supermarkets can support or incentivise beyond compliance in the Scottish salmon farming industry? If so, how?

13. How willing is your company to support innovation and development of the Scottish salmon farming industry? E.g. involvement in trials of new technologies, investment in R\&D. Sliding scale from 1 (Not willing) to 5 (Very willing)

13a. If applicable, please provide further details on the type of support your company would be willing to provide (or is already providing) in terms of industry innovation and development.

14. Do you think supermarkets can play a role in changing the negative public and media perception of the Scottish salmon farming industry? If so, how?

15. Is there anything else you would like to share that you think is relevant to this research? Any documents can be sent to *******@students.stir.ac.uk 